\title{
PEMBACAAN DANGDING HAJI HASAN MUSTAPA TERHADAP SASTRA SUFISTIK SUNDA DI ERA BUDAYA POPULAR
}

\author{
Jajang A. Rohmana \\ Universitas Islam Negeri Sunan Gunung Djati Bandung, Indonesia \\ E-mail: jajang_abata@yahoo.co.id
}

\begin{abstract}
Dangding as a literary work is only meaningful when chanted. When one just reads in his/her mind silently, dangding becomes dry and lacks of meaning. This paper discusses the position of Mustapa's dangding in literary context and their relevance to contemporary Sundanese discourse. The main focus of this study is the character of his mystical verses, structural aspects of dangding as a Sufism vessel, and to examine any discrepancy of meaning in reading process on his dangding for Sundanese literary today. Cultural studies approach is used to analyze the meaningfulness of his works in the current widespread popular cultural challenges. The study finds that with the decline of dangding tradition, Mustapa's works receive a great deal of challenges seen from the development of modern literary: the influence of Indonesian literature (short stories, novels, etc.) to the Sundanese literary; dangding becomes marginalized along with the loss of many cultural institutions where it is appreciated; and the problem of meaning discrepancies on reading it in popular culture, which is dominated by massively printed works that lost the meaning behind words and melody. It is difficult for it to compete in popular cultural hegemony that relies on uniformity, profit-oriented and passive consumer.
\end{abstract}

Keywords: Dangding, Sundanese, tasawuf, print culture.

\section{Pendahuluan}

Di antara berbagai kategori sastra klasik Nusantara, sastra keagamaan (Islam) kiranya belum begitu banyak mendapat perhatian. Padahal dari berbagai naskah Islam Nusantara, naskah sastra keagamaan terutama tasawuf, jumlahnya relatif banyak. ${ }^{1}$ Jasa besar

\footnotetext{
${ }_{1}$ Oman Fathurahman, Tarekat Shattariyah di Minangkabau (Jakarta: Prenada Media, EFEO, PPIM, KITLV, 2008), 17.
} 
para sufi kiranya tidak bisa dinafikan dalam mengembangkan tradisi intelektual Islam, termasuk di dalamnya tradisi sastra sufistik Nusantara. $^{2}$ Sastra sufistik memiliki pengaruh besar dalam perkembangan bahasa dan sastra Nusantara. Sastra Melayu klasik misalnya, harus mengakui kontribusi besar sastra sufistik dalam mengembangkan kesadaran dirinya melalui ajaran tentang yang indah, berfaedah, dan sempurna. ${ }^{3}$

Namun, dibandingkan dengan karya sastra sufistik Melayu, perhatian terhadap sastra sufistik Sunda relatif masih ketinggalan. ${ }^{4}$ Salah satunya adalah karya sastra sufistik Haji Hasan Mustapa (18521930). Ia adalah sastrawan Sunda terbesar dengan lebih dari 10.000 bait puisi dangding atau guguritan sufistik. ${ }^{5}$ Sebuah karya sastra Sunda yang lahir dari proses pencarian spiritualitas yang masih terus dipublikasikan hingga sekarang.

Dangding adalah karya puisi tembang yang dikarang dengan aturan kaidah pupub tertentu. Sebagai sebuah karya tembang, semula dangding sufistik Mustapa biasa disenandungkan dalam nyanyian. Namun, kehadiran teknologi cetak merubah tradisi tembang ini. Publikasi buku-buku guguritan sufistik Mustapa hadir di hadapan pembaca yang membacanya dalam diam (silent reading). ${ }^{6}$ Dangding-nya yang semula

2 Azyumardi Azra, The Origins of Islamic Reformism in Southeast Asia: Networks of MalayIndonesian and Middle Eastern 'Ulama' in the Seventeenth and Eighteenth Centuries (Honolulu: ASAA-Allen \& Unwin and University of Hawai'i Press, 2004), 2; dan A.H. Johns, "Sufism as a Category in Indonesian Literature and History", Journal of Southeast Asian History, Vol. 2, No. 2, Indonesia, 10-23.

${ }^{3}$ Liaw Yock Fang, Sejarah Kesusasteraan Melayu Klasik (Jakarta: YOI, 1991), 380; dan V.I. Braginsky, Yang Indah, Berfaedah, dan Kamal: Sejarah Sastra Melayu dalam Abad 719, terj. Hersri Setiawan (Jakarta: INIS, 1998), 435.

4 Penjelasan tentang sastra sufistik Melayu dapat dilihat, misalnya, dalam Syed Muhammad Naguib Al-Attas, The Mysticism of Hamzah Fansuri (Kuala Lumpur: University of Malaya Press, 1970); dan V.I. Braginsky, "Some Remarks on the Structure of the Syair Perahu by Hamzah Fansuri", Bijdragen tot de Taal-, Land-en Volkenkunde 131, No. 4 (1975), 407-426.

5 Ajip Rosidi, "Menjejaki Karya-karya Haji Hasan Mustapa", dalam Ahmad Rifa’i Hassan (ed.), Warisan Intelektual Islam Indonesia: Telaah atas Karya-karya Klasik. (Bandung: Mizan, 1992), 84.

${ }^{6}$ Lihat misalnya Haji Hasan Mustapa, Dangding Djilid Anu Kaopat (Bandung, t.p., 1960); Haji Hasan Mustapa, Gendingan Dangding Sunda Birabi Katut Wirahmana Djilid A (Bandung: Jajasan Kudjang, 1976); Iskandarwassid, Ajip Rosidi, Josef CD, Naskah Karya Haji Hasan Mustapa (Bandung: Proyek Sundanologi, 1987); Ajip Rosidi, Haji Hasan Mustapa Jeung Karya-karyanya (Bandung: Pustaka, 1989); Haji Hasan Mustapa, Seri Guguritan Haji Hasan Mustapa (Bandung: Kiblat, 2009), dan lainnya. 
merupakan wadah pengungkapan suasana batin berubah menjadi bacaan yang kaku dan kering. Terjadi pergeseran yang signifikan, dari karya estetika adiluhung menjadi bacaan populer dan komersil. Tiada lagi terasa suasana batin dalam alunan tembang dengan diiringi suara kecapi-suling. Sebuah suasana yang kiranya tidak lagi hadir dalam tradisi keberaksaraan cetak (print literacy) saat ini.

Tulisan ini memokuskan pada karya dangding Mustapa dilihat dari problematika pembacaannya di era budaya popular. Sebuah era di mana karya diproduksi secara massal melalui proses industrialisasi. Meski dalam beberapa kajian nama Mustapa dan dangding sufistiknya cukup dikenal, namun problem pembacaan atas karyanya dalam konteks budaya saat ini belum banyak dikaji. ${ }^{7}$ Mikihiro kiranya yang pertama merintis kajian efek keberaksaraan cetak dalam tradisi sastra Sunda. ${ }^{8}$ Itupun tidak khusus terkait dengan karya dangding Mustapa. Kajian ini mencoba memperkuat tesis Mikihiro bahwa keberaksaraan cetak merubah kesadaran akan bentuk apresiasi literasi sastra, dari seni lisan ke aksara. ${ }^{9}$ Kini kita harus terbiasa untuk mengenal dan merasakan nilai kesusastraan dalam tulisan. Sebuah konsekuensi besar yang semakin mempersulit tingkat apresiasi khususnya atas karya dangding sufistik Mustapa.

\section{Mustapa dan Dangding Sufistik Sunda}

Dangding merupakan bentuk puisi Sunda yang dikarang dengan mengacu pada pola kaidah 17 jenis pupuh. Ia berisi berbagai hal, seperti cerita (hikayat, roman) atau uraian agama. ${ }^{10}$ Seperti halnya

7 Lutfi Abas, "Prolegomena to Haji Hasan Mustapa's Mystical Cantos". Paper presented at a seminar in The Department of Malay Studies on October 6, 1976; Jajang Jahroni, "The Life and Mystical Thought of Haji Hasan Mustafa (18521930)" (Tesis--Leiden University, 1999; dan Ahmad Gibson al-Bustomi, Eksistensi Manusia menurut K.H. Hasan Mustapa (Tesis--UIN Sunan Gunung Djati, Bandung, 2009).

${ }^{8}$ Mikihiro Moriyama, Semangat Baru: Kolonialisme, Budaya Cetak, dan Kesastraan Sunda Abad ke-19, terj. Suryadi (Jakarta: KPG, 2005).

9 "Ketika Sastra Dicetak: Perbandingan Tradisi Tulisan Tangan dan Cetakan dalam Bahasan Sunda pada Paruh Kedua Abad ke-19". Konferensi Kesusastraan XV, Fakultas Sastra Universitas Sam Ratulangi Manado, 2004a, 1.

10 Ketujuh belas bentuk puisi pupub tersebut adalah Asmarandana, Balakbak, Dangdanggula, Durma, Gambuh, Gurisa, Jurudemung, Kinanti, Ladrang, Lambang, Magatru, Maskumambang, Mijil, Pangkur, Pucung, Sinom, dan Wirangrong. Pupub inilah yang kemudian melahirkan karangan berbentuk wawacan dan guguritan. Pupuh karenanya sangat terikat oleh nama, sifat (karakter), jumlah larik (padalisan) tiap bait (pada), jumlah suku kata (guru wilangan) pada setiap baris, bunyi vokal pada setiap 
macapat di Jawa, dangding dan wawacan biasa ditembangkan atau disenandungkan, bahkan pada acara yang dihadiri orang banyak (mamaos atau beluk), seperti melahirkan, mencukur bayi, memperingati hawl Shaykh 'Abd al-Qâdir al-Jîlânî, dan lain-lain. ${ }^{11}$ Sebagai sebuah karya sastra, dangding tidak terlepas dari pengaruh Islam dan budaya Jawa pasca-jatuhnya Kerajaan Sunda oleh Cirebon, Banten, dan Mataram pada 1579. Dangding bisa dianggap menjadi ciri keterpelajaran orang Sunda dalam menyerap pengaruh budaya Jawa. Sebagaimana Bujangga Manik, seorang bangsawan Sunda yang melakukan perjalanan ke Jawa dan Bali, dikenal "bisa carek Jawa" (pandai berbahasa Jawa) seperti diceritakan dalam naskah abad ke$16,{ }^{12}$ maka berkembangnya dangding juga menunjukkan kemampuan itu dan menjadikannya sebagai salah satu bagian kekayaan budaya Sunda.

Secara umum, dangding banyak dikembangkan oleh kalangan ménak Sunda. R.H. Muhammad Musa (1822-1886), Hoefd Penghulu Limbangan Garut, sastrawan Sunda pertama yang memublikasikan karya sastra berbentuk wawacan. R.A.A. Kusumaningrat alias Dalem Pancaniti, Bupati Cianjur (1834-1863) juga menulis surat kepada isterinya dalam bentuk dangding. ${ }^{13}$ Demikian pula Mustapa saling berkirim surat dengan rekannya, Kiai Kurdi, mengenai masalahmasalah agama dalam bentuk dangding. ${ }^{14}$ R.A.A. Martanagara, Bupati Bandung (1893-1918) yang banyak menulis wawacan, piwulang, dan babad, R.A.A. Wiranatakusumah (1888-1965), bupati Bandung zaman kolonial, menyusun buku Soerat al-Baqarah dan Riwajat Kangdjeng Nabi Moehammad saw (1941) yang berbentuk dangding — kreativitas literer yang dewasa ini diteruskan oleh Hidayat Suryalaga (w. 2011) dengan adaptasinya atas seluruh isi kitab suci itu dalam bentuk

akhir baris (guru lagu). Lihat Ma'mur Danasasmita, Wacana Bahasa dan Sastra Sunda Lama (Bandung: STSI Press, 2001), 171-172.

11 Ajip Rosidi, Mencari Sosok Manusia Sunda (Bandung: Pustaka Jaya, 2010), 30-31, dan 194.

${ }^{12}$ J. Noorduyn, dan A. Teeuw, Tiga Pesona Sunda Kuna, terj. Hawe Setiawan (Jakarta: Pustaka Jaya, 2006).

13 Nina H. Lubis, Kebidupan Menak Priangan 1800-1942 (Bandung: Pusat Informasi Kebudayaan Sunda, 1998), 240-241.

${ }^{14}$ Haji Hasan Mustapa, Bale Bandung (Bandung: Rahmat Cijulang, 1984). 
dangding. ${ }^{15}$ Namun dari sekian banyak menak Sunda yang menulis dangding, hanya Mustapa yang sangat kental dengan tradisi sastra sufistik Sunda.

Mustapa adalah sastrawan Sunda terbesar yang menulis lebih dari 10.000 bait puisi sufistik Sunda. Mustapa pernah tinggal lama di Mekkah bergabung dengan komunitas Jawi, lalu berkeliling Jawa menemani Snouck Hurgronje, hingga diangkat sebagai penghulu besar di Kutaraja Aceh dan Bandung. Kedekatannya dengan Snouck tidak dapat diabaikan karena ia menjadi salah satu tokoh kunci yang membuka informasi tentang Islam lokal. Mustapa merupakan salah satu informan pribumi yang memberi kemudahan bagi Snouck untuk masuk ke sisi terdalam Islam dan Muslim di Hindia Belanda. ${ }^{16}$ Kedudukan Mustapa sebagai elite penghulu Priangan menjadikannya masuk ke dalam lingkaran kaum ménak dan pada gilirannya lingkaran kolonial. $^{17}$

Secara genealogis, karir kesarjanaan Islam Mustapa tidak bisa dilepaskan dari jaringan Nawawi al-Bantani (1813-1879). Di Mekkah, ia disebut pernah bertemu Nawawi setelah sebelumnya saat remaja, ia dikabarkan pernah belajar pada Khalil Bangkalan, murid Nawawi. Elemen Banten kiranya memiliki tempat khusus terutama dalam konteks jaringan ulama Jawi Nusantara abad ke-19. Sayyid Ulama alHijaz ini dianggap sebagai ulama arsitek intelektual pesantren berkat karya-karyanya. ${ }^{18}$

Latar kehidupan Mustapa sangat berpengaruh terhadap dangding sufistiknya. Harus diakui Mustapa memang berasal dari keluarga pesantren sekaligus keluarga yang akrab dengan tradisi budaya Sunda. ${ }^{19}$ Ia juga dianggap banyak dipengaruhi tradisi mistisisme Islam Nusantara (seperti Hamzah Fansuri, al-Sumatrani, Nuruddin al-Raniri, dan 'Abdurrauf al-Jawi) setidaknya setelah berkarir di Aceh (1892-

\footnotetext{
${ }^{15}$ Hawe Setiawan, "Cangkang Suluk Dangding Haji Hasan Mustapa sebagai Wadah Mistisisme Islam", makalah dalam Sawala Mesek Karya Haji Hasan Mustapa, UIN Bandung, 2009.

${ }^{16}$ Michael Francis Laffan, Islamic Nationhood and Colonial Indonesia: The Umma below the Winds (London, New York: Routledge Curzon, 2003), 82-84; dan Jajat Burhanudin, Ulama dan Kekuasaan: Pergumulan Elite Muslim dalam Sejarah Indonesia (Bandung: Mizan, 2012), 158.

${ }^{17}$ Lubis, Kebidupan, 289.

18 Abdurrahman Mas'ud, Intelektual Pesantren: Perbelatan Agama dan Tradisi (Yogyakarta: LKiS, 2004), 95-132.

19 Tini Kartini, et al., Biografi dan Karya Pujangga Haji Hasan Mustapa (Jakarta: Pusat Pembinaan dan Pengembangan Bahasa Depdikbud, 1985), 13.
} 
1895). ${ }^{20}$ Boleh jadi pula tradisi sastra suluk Jawa memberinya inspirasi setelah mengikuti perjalanan mendampingi Snouck Hurgronje (18871889/1889-1890). ${ }^{21}$ Meskipun besar kemungkinan ia juga sudah mengetahui tentang tradisi tasawuf seperti tampak pada karya Ibn 'Arabî, 'Abd al-Karîm al-jilî, Abû Hâmid al-Ghazâlî, dan alBurhânfûrî selama dua belas tahun karirnya di Mekkah (1860-1862, 1869-1873, 1877-1882). ${ }^{22}$

Konsentrasinya pada mistisisme Sunda begitu mencengangkan bila melihat rentang waktu disusunnya ribuan guguritan mistik Mustapa (1900-1902). ${ }^{23}$ Dibandingkan karya prosanya, puisi dangding Mustapa ternyata masih belum banyak yang tersentuh. Dari sekitar 10.000 bait, belum seluruhnya ditransliterasi dan di-publish. Selain karena bahasa Sunda yang digunakannya cukup sulit bagi orang Sunda umumnya, juga naskahnya sendiri yang beraksara pegon sebagiannya masih tersimpan di UB Leiden. Namun, sebab lain yang tidak kalah penting adalah tema sufistik Sundanya yang cenderung pada tema besar wahdat al-wujûd. Bahasa simbolis sufistik Mustapa disajikan ke dalam bentuk dangding, sehingga dibutuhkan sarjana yang mumpuni, tidak saja di bidang bahasa dan sastra Sunda bahkan Jawa, tetapi juga ahli di bidang keislaman khususnya tasawuf.

Berdasarkan catatan katalog Naskah Sunda, naskah-naskah dangding Mustapa ditandai dalam Cod. Or. 7872-7879 dan diberi judul Kepercayaan dan Mistik atau dalam inventarisasi R.A. Kern ditandai dengan "over geloofsleer en mystiek" (bab kepercayaan dan mistik). ${ }^{24}$ Kiranya naskah salinannya termasuk ke dalam naskah periode terakhir dilihat dari rentang beredarnya naskah Sunda antara abad ke-14 hingga akhir abad ke-20 M. Aksara pegon yang digunakannya dalam

\footnotetext{
20 Ajip Rosidi, Manusia Sunda (Bandung: Kiblat Pustaka Utama, 2009), 153.

21 Penjelasan tentang sastra suluk Jawa dapat dilihat dalam P.J. Zoetmulder, Manunggaling Kawula Gusti, Pantheisme, dan Monisme dalam Sastra Suluk Jawa, terj. Dick Hartoko (Jakarta: Gramedia Pustaka Utama, 1991); Simuh, Mistik Islam Kejawen Raden Ngabehi Ranggawarsita (Jakarta: UI Press, 1988); dan S. Soebardi, The Book of Cebolek (Leiden: KITLV-The Hague-Martinus Nijhoof, 1975).

22 Jahroni, "The Life", 24, dan 41.

23 Ajip Rosidi (ed.), Ensiklopedi Sunda: Alam, Budaya, dan Manusia (Jakarta: Pustaka Jaya, 2003), 263.

24 Edi S. Ekadjati, Naskah Sunda: Inventarisasi, dan Pencatatan (Bandung: Lembaga Penelitian Unpad-The Toyota Foundation, 1988), 213.
} 
naskah karenanya berada dalam situasi kemunduran karena semakin terdesak oleh aksara Latin. ${ }^{25}$

Selain koleksi UB Leiden, naskah salinan karya guguritan Mustapa juga terdapat di Perpusnas Jakarta dan koleksi individu. Salah satunya adalah hasil salinan M. Wangsaatmadja, sekretaris Mustapa. Hasil suntingannya itu diberi judul Aji Wiwitan I-IV. Sayangnya Wangsaatmadja menyalinnya ke dalam aksara Roman dan kemudian naskah asli tulisan tangan Mustapa dimusnahkannya. ${ }^{26}$

Publikasi dangding-dangding Mustapa umumnya dilakukan Ajip Rosidi. Ia memulainya dengan memublikasikan hasil karya berbentuk stensil pada 1960 berjudul Dangding Djilid nu Kaopat memuat empat belas pupuh. Lalu Haji Hasan Mustapa jeung Karya-karyana (1989) yang memuat lima pupuh, dan suntingan Ruhaliah atas naskah dangding Mustapa dari UB Leiden dalam Seri Guguritan Haji Hasan Mustapa (2009) yang baru menerbitkan lima pupuh. Selain itu, Iskandarwassid dan Josef C.D. (1987) sempat juga memublikasikan suntingan sembilan pupub dari UB Leiden.

\section{Struktur dan Pesan Dangding}

Pembahasan tentang aspek sastra dalam dangding Mustapa kiranya sudah cukup banyak dikupas. Rosidi dan juga Setiawan mencatat bahwa rancang bangun dangding Mustapa memiliki kekhasan dilihat beberapa segi: Pertama, diksi dalam dangding yang dibangun dengan kreativitas pilihan kata yang seringkali tidak terduga. Misalnya imbuhan -um pada banyak kata yang tidak biasa, imbuhan -ing sebagai pengaruh bahasa Jawa yang dikelola secara kreatif, dan pengaruh bahasa Arab bercitarasa sufistik bersumber dari ayat atau hadith yang kerap menghiasi larik dangding-nya (iqtibâs). Kedua, secara struktur, baitbait dangding Mustapa kerapkali menggunakan sampiran sebagai pembuka layaknya rajah dalam pantun Sunda. Sampiran yang tampak liar dan berkelok-kelok rata-rata sulit dibaca bila dihubungkan dengan tema pokok dangding-nya. Seringkali diletakkan di bagian awal dangding, meski kadang menyelip tiba-tiba di tengah-tengah, sehingga fungsinya lebih sebagai interlude. ${ }^{27}$

25 Edi S. Ekadjati, "Sundanese Manuscripts: Their Existence, Functions, and Contents", Journal of the Centre for Documentation \& Area-Transcultural Studies, 2 (2003), 125-126.

${ }^{26}$ Kartini, et al., Biografi, 39.

27 Setiawan, "Cangkang Suluk", 7-10. 
Rancang bangun dangding Mustapa juga sangat kuat dalam permainan mengolah bunyi kata yang bersuara nyaris sama dan jumlahnya terbatas. Ibarat bermain musik, kata-kata itu diulang-ulang tanpa beranjak sedikitpun dari aturan pupub dan subject matter yang ingin disampaikannya. Sebagai bujangga, seringkali dangding-nya juga disisipi sisindiran (larik yang terdiri dari sampiran dan isi layaknya pantun Melayu) dan wawangsalan (larik yang mengajak pembaca menebak isi berdasarkan bunyi kata yang digunakan). Seringkali dangding Mustapa juga menggunakan satu kata akhir dari setiap bait sebagai kata pembuka bait berikutnya, sehingga terlihat berkesinambungan. Tidak hanya antar-bait, kadang Mustapa juga menggunakannya antar-larik.

Namun, puisi tembang yang lahir secara spontan secara tak terhindarkan menyisakan persoalan pada ketidakterkendaliannya sebaran ilustrasi sufistik di berbagai dangding-nya. Pada beberapa dangding, gagasan yang sama kadang diulangnya. Ini bisa dipahami terkait dengan ketatnya aturan ририһ dan suasana spiritualitasnya yang timbul tenggelam, sehingga banyak dangding-nya yang tidak beranjak dari tema suluk. Selain itu, kadang akhirnya pembatasan aturan tersebut mengungkung atau justru beberapa dilampauinya. Misalnya dalam hal kutipan ayat atau hadîth (iqtibâs), seringkali memaksanya untuk memodifikasi redaksinya disesuaikan dengan jumlah suku kata atau bunyi ujung larik. ${ }^{28}$

Dilihat dari materi dangding-nya, karya ulama mabiwal (lain dari yang lain) ini kiranya penting dilihat dalam konteks sastra sufistik yang bercitarasa budaya Sunda dengan menggunakan dangding sebagai wadahnya. Signifikansi karyanya tampak pada penggunaan media sajak bermatra (metrical verses) tersebut untuk menuturkan perjalanan spiritualnya (suluk) dari pencarian hingga pencapaian. Ia menggunakan berbagai citra dan simbol yang terdapat dalam alam pikiran Sunda terutama lingkungan alam Priangan yang diselaraskan dengan alam keislaman yang diyakininya. Sebagaimana citra dan simbolisme dalam syair-syair sufistik Melayu yang mencerminkan karakter bangsa pelaut, maka puisi sufistik Sunda karya Mustapa meminjam bahasa Braginsky pada sastra suluk Jawa, sering mengemukakan simbol setempat yang

${ }^{28}$ Misalnya Mustapa, Seri Guguritan, 31. 
luar biasa. ${ }^{29}$ Zoetmulder sudah menunjukkan aneka simbolisme luar biasa dalam sastra suluk Jawa. ${ }^{30}$

Nuansa alam ke-Sunda-an seperti flora dan fauna digunakan secara simbolis untuk mengungkap suasana batinnya. Ia berusaha menghubungkan alam luar dengan dirinya (mikrokosmos). Dalam berbagai dangding-nya, ia misalnya menggunakan metafor hewan (buruy/kecebong, manuk/burung, hayam-endog/ayam-telur) atau tumbuhan (iwnng dan bambu, dunvegan dan kitri, beras dan padi, sirung dan benih, aren dan caruluk, tongtolang/biji nangka dengan nangka). Metafor kecebong misalnya, tampak pada salah satu dangding Kinanti Teu Kacatur Berikut. ${ }^{31}$

Teu jauh ti buruy ngambul

Bijil ti cai ka cai

Kasasar lamun misaha

Kasasar lamun mikir

Kumaha alam luarna

Jagana baring supagi

Tidak beda dari kecebong yang muncul

Muncul dari air ke air

Tersesat kalau mempertanyakan siapa

Tersesat kalau berpikir

Bagaimana alam luarnya

Nantinya besok atau lusa buruy berarti kecebong atau berudu. ${ }^{32}$ Kecebong digunakan Mustapa untuk menunjukkan suasana spiritual (hâh) yang dirasakannya ketika belajar melakukan pencarian hakikat dirinya yang sewaktu-waktu muncul sebentar kemudian menghilang timbul tenggelam. Mustapa seakan ingin mengatakan bahwa proses pencarian itu tidak gampang. Perlu banyak latihan dan kesabaran, karena tidak semua sâlik (traveler, pelaku suluk) berhasil melewati tahap ini. Ibarat kecebong, yang semula berjumlah besar, tetapi tidak semua berhasil melewati fase tersebut. Hanya beberapa kecebong saja yang berhasil berubah menjadi kodok dewasa dan beralih ke daratan. Hanya beberapa sâlik saja yang berhasil melampaui alam zahir, masuk

\footnotetext{
${ }^{29}$ Braginsky, Yang Indah, 494.

30 Zoetmulder, Manunggaling, 284-320.

${ }^{31}$ Haji Hasan Mustapa, Kinanti Tutur teu Kacatur Batur, MS. Or. 7875, UB Leiden, 16 Agustus 1901.

32 Boeroej, larve van een kikvorsch; ook: jonge kikvorsch (Vgl: boejoer en tjebong). Lihat S. Coolsma, Soendaneesch-Hollandsch Woordenboek (Leiden: A. W. Sijthoff's Uitgevers-Maatschappij, 1913), 95.
} 
ke ragam fase spiritualitas (maqâmât) dan mencapai tahap penemuan puncak hakikat spiritual alam sejati (fanâ' fì al-ḥaqq). ${ }^{33}$

Ungkapan sufistik lainnya yang menggunakan citra dan simbol alam Sunda yang subur tampak pada penggunaan ekspresi metaforik flora berupa bambu (bambusa Sp.div) dengan aneka jenis, dan beragam tumbuhan lainnya. Mustapa misalnya menyebut angklung yang sengaja dibedakan dengan bambu biasa (awr) ketika menggambarkan keserasian kondisi dirinya dengan Tuhan. ${ }^{34}$

Puguh angklung ngadu angklung

Bisa uni teu jeung awi

Balukarna lalamunan

Mun biji misah ti biji

Ngan kari pada capétang

Ngawayangkeun abdi Gusti

Jelas angklung mengadu angklung

Bisa bunyi (indah) bukan dengan bambu

Sebabnya dari lamunan

Kalau yang satu pisah dari yang satu

Cuma sekadar pandai berbicara

Mewayangkan hamba Gusti Angklung adalah salah satu instrumen musik Sunda yang terbuat dari bambu. ${ }^{35}$ Ia dianggap sebagai instrumen musik asli dari Priangan. Terdiri dari dua atau tiga bambu pendek berukuran sedang yang diletakkan dalam bingkai persegi empat. Cara memainkannya adalah dengan menggoyanggoyangkannya. Bunyi dihasilkan dari getaran bambu-bambu yang saling beradu. ${ }^{36}$

Mustapa menggunakan angklung sebagai metafor untuk menggambarkan kondisi dirinya pada saat pencarian hakikat diri. Ia menyadari penemuan itu terjadi ketika dirinya bisa menjaga kesucian diri. Dalam bait sebelumnya, ia menyebutkan bahwa Tuhan tersembunyi dalam diri manusia (al-sirr al-insânî) yang hadir sesuai persangkaan hamba-Nya (wa anâ fì zann 'abdì). Kehadirannya semakin kuat disuarakan oleh yang dalam kondisi diri yang suci sebagaimana Tuhan. Terjadi pertemuan yang seimbang antara kesucian diri dengan

\footnotetext{
${ }^{33}$ Reynold A. Nicholson, The Mystics of Islam (Indiana: World Wisdom, 2002), 21.

${ }^{34}$ Mustapa, Kinanti, 9.

35 Angkloeng, naam van een muziek-instrument (en wel een schudinstrument), vervaardigd van bamboepijpen. Lihat S. Coolsma, Soendaneesch-Hollandsch, 28.

36 Henry Spiller, Gamelan: The Traditional Sound of Sunda (California: ABC-CLIO, 2004), 137-140.
} 
kesucian Tuhan. Ibarat instrumen musik angklung yang bertemu dengan angklung akan menghasilkan bunyi irama yang indah.

Mustapa membedakan angklung dengan awi dalam konteks wabdat al-wujûd, yakni sebagai gambaran metaforik aspek manusia (nâsût) dan aspek ketuhanan (lâhût) dalam dirinya. Jarak keduanya dianggap tidak terbatas. Suluk merupakan sebuah perjalanan dari nâsût ke lâhût. Dari awi ke angklung. Ia berasal dari Tuhan dan harus kembali ke Tuhan. Ia seperti bermain metafor seputar kedua aspek ini dengan logika paradoksal antara bentuk (form) dan isi (essence). Pada aspek ketuhanan terdapat aspek manusia, dan demikian pula sebaliknya. ${ }^{37}$

Kiranya menarik bila metafor buruy dan angklung sebagai gambaran proses pencarian diletakkan dalam konteks tasawuf wahldat al-wujûd. Dalam konsep kontemplasi Ibn 'Arabi, suasana spiritual itu merupakan tahapan di mana pancaran hati yang tiba-tiba dihasilkan melalui tindakan timbal-balik antara sinaran ketuhanan dengan kesiapan hati itu sendiri (isti'dâd). Singkat-tidaknya atau stabil-tidaknya sangat ditentukan oleh kedua kutub ini. Kutub mana dari keduanya yang akan muncul sebagai faktor menentukan atau ditentukan. ${ }^{38}$ Kecebong dan angklung kiranya gambaran yang sangat tepat dalam mengungkapkan suasana itu, karena lahir dari apa yang dalam bahasa Corbyn disebut sebagai imajinasi kreatifnya sebagai mistikus Sunda. ${ }^{39}$

Metafor hewan seperti kecebong dan jenis fauna lainnya menunjukkan keterikatan Mustapa sebagai orang Sunda yang hidup dengan lingkungan alam Sunda. Sebuah alam yang ditemuinya dengan kekayaan flora dan fauna di tengah alam yang subur. Masa kecilnya dihabiskan di tengah alam pegunungan Garut dengan hutan, aliran sungai dan kolam. Alam Sunda yang dalam bahasa Wittfogel (1936) disebut sebagai tempat tinggal bydrolic society. ${ }^{40}$ Karena kesuburannya itu, wajar bila Brouwer, seorang rohaniawan Katolik, menyebut bahwa tatar Sunda terjadi ketika Tuhan tersenyum. ${ }^{41}$ Karenanya tema air (cai, ci) menjadi keumuman nama tempat di tatar Sunda dan seringkali ditemukan dalam dangding-nya.

\footnotetext{
${ }^{37}$ Jahroni, “The Life", 62-63.

38 Titus Burckhardt, Introduction to Sufi Doctrine (Indiana: World Wisdom, 2008), 97.

${ }^{39}$ Henry Corbyn, Alone with the Alone, Creative Imagination in Sufism of Ibn 'A rabi, terj. Ralph Manheim (Princeton: Princeton University Press, 1969).

${ }^{40}$ Haryoto Kunto, Semerbak Bunga di Bandung Raya (Bandung: PT. Granesia, 1986), 87.

${ }^{41}$ M.A.W. Brouwer, Perjalanan Spiritual dari Gumujeng Sunda, Eksistensi Tuhan, sampai Siberia (Jakarta: KPG, 2003), 1.
} 


\section{Dangding Sufistik sebagai Tembang Spiritual}

Selain pesan sufistik alam ke-Sunda-an, membaca dangding Mustapa kiranya mesti didudukkan dalam posisinya sebagai tembang yang dilagukan. Suasana saat ketika ia membaca puisi dengan bersuara dan menyanyikannya dalam lagu dengan penuh penghayatan, bukan membaca dalam hati (silent reading) dan mendaraskannya. ${ }^{42}$ Dangding berupa pириһ sebagai tembang sebagaimana dikatakan van Zanten, sepenuhnya diadopsi dari budaya Jawa. Meskipun istilah tembang sendiri bagi masyarakat Sunda memiliki perbedaan karena mencakup pula seni tradisi seperti tembang Cianjuran, papantunan, dan lainnya. ${ }^{43}$ Dangding karenanya bukan sekadar konstruksi verbal tetapi juga konstruksi musikal. Terjadi persenyawaan antara ekspresi spiritual dengan cita rasa seni manakala dangding dialunkan. Biasanya dengan iringan kecapi atau instrumen musik lainnya, citra, dan simbolisme lokal yang bersumber dari kekayaan batin orang Sunda begitu mudahnya keluar secara spontan. Dalam mabuk spiritual (extase, fanâ), dangding mengalir bak arus air. Tidak saja sangat sesuai dengan aturan metrum puisinya yang bermelodi, tetapi juga padat dan kaya makna karena disenyawakan dengan permenungan mistiknya. ${ }^{44}$

Dangding Mustapa sebagai wadah mistisisme benar-benar merupakan puisi bermutu tinggi yang penuh metafor, purwakanti, yang menimbulkan asosiasi berlapis-lapis dan seakan-akan mengalir secara alami. Semuanya terasa wajar keluar dari imaji pikiran dan mentalnya dengan memenuhi segala kaidah puisi dangding yang sangat rumit. Puisinya lebih dari sekadar sastra, karena merupakan pertemuan antara ekspresi sufistik dengan puisi sebagai wadah atau cangkang suluk-nya. Di satu sisi ia merupakan ungkapan mistis, tetapi di sisi lain juga dituangkan ke dalam sebuah bentuk karya sastra puisi yang disesuaikan dengan sifat dan watak puisinya sendiri secara tepat.

Dangding Pangkur Pangkurangna Nya Hidayat misalnya, bercerita tentang kisah perjalanan hidup Mustapa dari kecil, dewasa hingga menjelang usia senja. Pangkur sendiri merupakan metrum puisi yang salah satunya digunakan untuk menggambarkan pengalaman menjalani hidup (lumampah). Begitupun dengan Kinanti Tutur Teu

\footnotetext{
42 Moriyama, Semangat Baru, 57.

${ }^{43}$ Wim van Zanten, "The Poetry of Tembang Sunda", Bijdragen tot de Taal-, Land- en Volkenkunde 140, No. 2/3 (1984), 294. Kajian tentang tembang Jawa dapat dilihat dalam Bernard Arps, Tembang in Two Traditions: Performance and Interpretation of Javanese Literature (London: School of Oriental and African Studies, 1992).

${ }^{44}$ Setiawan, "Cangkang Suluk", 2.
} 
Kacatur Batur, Tungtungna Ngaburun Balung, Jung Indung Turun Ngalayung, Puyuh Ngungkung dina Kurung banyak bercerita tentang suasana pencarian spiritual kemudian dituangkan ke dalam puisi Kinanti yang berwatak keprihatinan, harapan, dan penantian (nganti). Hal yang sama kiranya tampak pada Asmarandana Tadina Aing Pidohir, Kasmaran Dening Hakeki, al-Insanu Sirri, dan Babalik Pikir misalnya, yang menggambarkan kerinduan Mustapa akan sentuhan Ilahi dalam perjalanan suluk-nya sesuai dengan watak birahi (kasmaran) dalam metrum Asmarandana. Begitu juga dalam Dangdanggula Panorahan Rasa dan Amis Tiis Pentil Majapait yang menggambarkan ekspresi Mustapa akan keagungan Tuhan dan ajaran-Nya yang sampai di tatar Sunda. ${ }^{45}$ Di sini tampak terjadi penyatuan antara ekspresi sastra sufistik dengan suasana batin dalam suluk-nya sendiri. Efek puitika dangding Mustapa akan terasa sepenuhnya manakala dilantunkan dengan penuh penghayatan sesuai dengan jenis pupuh-nya.

\section{Problem Pembacaan di Era Budaya Popular}

Dangding sufistik Mustapa lahir dalam suasana transisi di mana budaya cetak mulai diperkenalkan Belanda pada awal abad ke-19 dan secara perlahan menggeser budaya naskah. Dangding sebagai bagian dari tradisi budaya bangsawan Sunda saat itu, secara berangsur-angsur kehilangan posisi dominannya. Sajak bermatra semacam ini yang semula dianggit sambil ditembangkan mulai tersisihkan ketika budaya cetak lahir. Mikihiro mencatat apa yang ia sebut sebagai efek penyusunan kembali kesadaran (restructures consciousness) yang jauh lebih dahsyat dari yang diperkirakan Belanda dan dirasakan hingga saat ini.

Keberaksaraan cetak (print literacy) kiranya telah mengubah unsur-unsur tradisi lisan dan penulisan beserta praksis-praksisnya. Keberaksaraan cetak menjadi wahana bentuk-bentuk baru dari unsur-unsur kebudayaan, mencangkokkan tradisi dengan modernitas. Pada bahasa sastra, cetakan menahan sifat menyimpang dan kelenturan bahasa, membakukan ciri kelisanan dan khirografik berbasis keberaksaraan. ${ }^{46}$

Budaya naskah adalah budaya di mana sifat oral-aural terasa begitu kuat. Para pembaca menyuarakan teks yang ditulis tangan yang diletakkan di hadapan mereka. Sering juga pembacaan naskah

45 Mustapa, Gendingan; Ajip Rosidi, Haji Hasan Mustapa jeung Karya-karyana, 1989; Momon Wirakusumah dan Buldan Djajawiguna, Kandaga Tata Basa Sunda (Bandung: Ganaco, 1957), 47.

${ }^{46}$ Mikihiro Moriyama, "Ketika Sastra Dicetak: Perbandingan Tradisi Tulisan Tangan dan Cetakan dalam Bahasan Sunda pada Paruh Kedua Abad ke-19". Konferensi Kesusastraan XV, Fakultas Sastra Universitas Sam Ratulangi Manado, 2004, 1. 
merupakan kegiatan bersama dan kadang kala diadakan dalam upacara adat ataupun ritual. Tradisi mamaos dangding (Jawa: mamacan) misalnya, sebuah tradisi di mana dangding dikarang dan didendangkan kadang secara bergantian dan spontan (ngagayem dangding), turut membentuk bangunan sastra sufistik Mustapa. Ia bersama Kiai Kurdi dan pernah secara bergantian melakukan tradisi ngagayem dangding ini hingga menghasilkan sebuah dangding yang populer, Guguritan Laut Kidul. ${ }^{47}$

Karenanya, pemahaman mendalam akan bentuk tradisi lisan dan tulisan seperti pembacaan dangding tersebut memungkinkan kita memahami secara lebih baik tentang dunia baru tulisan di era budaya popular. Lahirnya keberaksaraan cetak dan publikasi massal sebagai salah satu anak kandungnya saat ini yang merubah kesadaran akan bentuk apresiasi literasi sastra, dalam konteks pembacaan dangding, bukan merupakan proses kekuatan alamiah, tetapi kekuatan yang disusun melalui teknologisasi tulisan. Ong menyebutkan bahwa tulisanlah yang membuat pikiran peka dengan huruf serta mampu berpikir sebagaimana adanya. Tidak hanya terpaut dengan tulisan, tetapi ketika menyusun pikirannya dalam bentuk tradisi lisan, ${ }^{48}$ dan cetakan merubah segala kesadaran yang terkandung dalam tradisi dangding.

Perubahan tulisan dari keberaksaraan khirografik (naskah) ke cetak membuktikan secara kuat perubahan itu. Bisa dibilang ia sudah menggoncangkan jagat kehidupan orang Sunda. Mereka harus mendefinisikan kembali pengertian semula tentang seni-seni lisan, juga tentang "buku," dan harus membiasakan diri untuk mengenal dan merasakan nilai kesusastraan dalam tulisan. ${ }^{49}$ Terjadilah kesenjangan makna ketika dihadapkan pada publikasi cetak secara massal, setidaknya seperti tampak dalam publikasi intens sastra sufistik dangding karya Mustapa beberapa dekade ini. Dangding Mustapa yang semula lahir dari tangan dingin seorang mistikus sekaligus sastrawan ahli mamaos terasa kering. Curahan seluruh perasaan batinnya yang ditembangkannya ke dalam bait-bait puisi itu, kini nyaris tinggal kenangan. Hanya gumaman yang tidak bersuara mengejar deretan aksara yang tanpa makna.

\footnotetext{
${ }^{47}$ Ajip Rosidi, Guguritan (Bandung: Kiblat, 2011), 80-87.

48 Walter J. Ong, Orality and Literacy (London and New York: Routledge, 2002), 77.

49 Mekkah Moriyama, "Print Technology and Literacy in the Second Half of the 19th Century Sundanese Language Community of the Dutch East Indies", 15th Biennal Conference of the Asian Studies Association of Australia, Panel Media Literacy and Community Formation, Canberra: 2004, 15.
} 
Karenanya, seiring dengan semakin ditinggalkannya tradisi dangding ini, karya Mustapa mendapatkan banyak tantangan dilihat dari perkembangan sastra modern. Pertama, pengaruh tradisi sastra modern (cerpen, novel, dan lain-lain) terhadap sastra Sunda. Dangding semakin terdesak dan sulit bersaing dengan tradisi sastra modern, baik dilihat dari aspek kepengarangan maupun pembaca. ${ }^{50}$ Tahun 1914 saat novel Sunda pertama terbit, Baruang kanu Ngarora, merupakan momen awal yang menandai pergeseran itu. Sesudahnya muncul terjemah dan saduran cerita-cerita Eropa dan Melayu ke dalam bahasa Sunda. ${ }^{51}$

Sekuat apapun pemertahanan tradisi sastra tradisional, tetap tidak bisa menghindar dari berbagai konsekuensi arus sastra modern. Diperlukan komitmen kuat dalam merespons perubahan tersebut. Kegamangan justru membuahkan ambivalensi perubahan. Ini misalnya ditunjukkan dengan Geguritan Nengah Jimbaran yang berbahasa Melayu. Di satu sisi, ia berusaha mengikuti perkembangan sastra Indonesia modern yang didominasi cerpen dan novel, tetapi di sisi lain ingin pula mempertahankan identitas lokalitas sastra. ${ }^{52}$

Kemodernan yang ditandai cetakan memungkinkan karya sastra Sunda modern berupa carpon (carita pondok) atau novel Sunda misalnya, dianggap lebih efektif untuk diapresiasi pembaca dibanding sastra tradisional seperti dangding yang memerlukan iringan tembang. Semakin banyak karya sastra Sunda modern tersebut dicetak dan diproduksi, turut berpengaruh terhadap kebiasaan membaca.

Kedua, posisi dangding semakin terpinggirkan seiring dengan semakin hilangnya berbagai institusi budaya tempat dangding diapresiasi. Dahulu pembacaan dangding menjadi salah satu aktivitas yang dilakukan dalam ritual dan upacara tradisional (hajat) masyarakat Sunda pedesaan. Upacara tahunan ngaruwat bumi atau hajat lembur yang dilaksanakan jelang musim panen selalu diramaikan dengan pertunjukkan seni tradisional, seperti pertunjukkan carita pantun, beluk, atau wayang. Beluk merupakan salah satu jenis pembacaan cerita berbentuk wawacan semalam suntuk. ${ }^{53}$ Meskipun ia tidak seperti carita

\footnotetext{
${ }^{50}$ Yus Rusyana, et al., Lima Abad Sastra Sunda (Bandung: Geger Sunten, 2000), 25.

${ }^{51}$ Moriyama, Semangat Baru, 256.

52 Maya H.T. Liem, The Turning Wheel of Time: Roda Jaman Berputar, Modernity, and Writing Identity in Bali 1900-1970 (Leiden: Copy \& Printshop WSD, 2003), 93.

${ }^{53}$ Rosidi, Guguritan, 18-20.
} 
pantun yang merupakan tradisi lisan asli warisan leluhur orang Sunda. ${ }^{54}$ Bahkan bagi beberapa seniman Sunda, menembangkan dangding menjadi semacam ritual harian dalam mengisi waktu luang sebagai ungkapan perasaannya. Ngadangding biasanya dilakukan di tengah keheningan dengan diiringi alunan musik kecapi.

Ketiga, problem diskrepansi makna dalam pembacaan dangding dalam konteks budaya popular. Meminjam ungkapan Meij, dangding kini menjadi semacam "teks eksotis" di hadapan pembaca modern yang tidak lagi terlalu peduli dengan konteks aktual teks (tembang, tradisi lisan, dan tulisan), tetapi menciptakan konteks terbayang di sekeliling teks yang ada di hadapannya. ${ }^{55}$ Budaya konsumen yang didominasi hasil cetak mekanik massal tanpa tembang, tidak memungkinkan setiap orang merasakan makna di balik kata-kata dan melodi yang dialunkan dalam dangding. Ia semakin sulit bersaing di tengah hegemoni budaya populer yang berlatar kultur industri dan mengandalkan keseragaman, berorientasi profit dan menjadikan konsumen begitu pasif. ${ }^{56}$ Adorno menyebutnya sebagai komoditas fetisisme, di mana materi mampu menentukan dan mendominasi relasi sosial masyarakat kapital. ${ }^{57}$ Memproduksi dan membeli buku dangding merubah kepentingan apresiasi manusia Sunda yang semula bertujuan untuk meraih kepuasan rasa seni melalui tradisi salin naskah menjadi bentuk kultural yang menjaga kesinambungan dominasi ekonomi kapitalis. Tepat kiranya yang disampaikan Benjamin: "that which withers in the age of mechanical reproduction is the aura of the work of art...the technique of reproduction detaches the reproduced object from the domain of tradition". ${ }^{58}$

Dangding lahir dalam tradisi aktual masyarakat Sunda yang masih mengandalkan tradisi lisan dan tulisan (naskah) sekaligus menandai pergeserannya ke dalam tradisi cetak (mekanik). Kedalaman permenungan sangat ditekankan, karena perlu waktu untuk

\footnotetext{
${ }^{54}$ Andrew N. Weintraub, "Tune, Text, and The Function of Lagu in Pantun Sunda: A Sundanese Oral Narrative Tradition", Asian Music, Vol. 26, No. 1 (Autumn, 1994Winter, 1995), 175.

55 Th.C. van Der Meij, Puspakrema: A Javanese Romance from Lombok (Leiden: CNSW Publications, 2002), 194.

56 John Storey, Inventing Popular Culture (UK: Blackwell Publishing, 2003), 17.

57 Dominic Strinati, An Introductions to Theories of Popular Culture (London and New York: Routledge, 1995), 50.

${ }^{58}$ Walter Benjamin, Illuminations, Essays, and Reflections (New York: Schocken Books, 1969), 274.
} 
menghasilkan dan memahami makna di dalamnya. Karenanya revitalisasi sastra dangding Mustapa merupakan upaya sangat berat dilihat dari beberapa aspek tersebut. Sebuah perjuangan ke arah revitalisasi khazanah budaya Sunda yang mengarah pada pentingnya pertaruhan ideologi ke-Sunda-an.

\section{Penutup}

Sastra sufistik Sunda seperti tampak pada dangding Mustapa menunjukkan secara jelas kreativitas lokal sebagai jaringan halus dalam merespons tradisi intelektual tasawuf Nusantara. ${ }^{59}$ Melalui karyanya, ia menginterpretasikan pengalaman sufistik yang diungkapkan melalui karakteristik alam ke-Sunda-an. Sebuah gambaran resepsi Islam yang tidak lagi dikotomis dan di permukaan. ${ }^{60}$ Bujangga Sunda terbesar ini, karenanya, memiliki kontribusi penting dalam proses indegenisasi Islam Nusantara. Di tangannya, tampak harmonisasi ajaran Islam dengan alam pikiran Sunda.

Namun, sayangnya tidak banyak orang Sunda yang mengenal sosok sufi soliter ini dengan segala kekhasan ekspresi sufistiknya itu. Mustapa kini kiranya hanya dikenal sebagai nama populer salah satu jalan di Bandung (Jl. PHH. Mustapa). Selain karena akses yang terbatas, kerumitan bahasa sastra, dan konsep tasawufnya kiranya pula menjadi alasan kesulitan untuk mengkaji karya-karya dangding-nya. Terlebih membaca sastra berbentuk dangding ini terasa bermakna ketika ditembangkan, baik perorangan maupun bergantian. Kering rasanya bila sekadar dibaca dalam hati (diilo) dalam kesunyian dari tulisan cetak. Pada saatnya, suara menjadi hening dan dangding semakin kehilangan perannya dalam khazanah sastra Sunda.

Karenanya, konteks tembang sebagai ungkapan spiritualitas mistik sama sekali tidak bisa diabaikan dalam mengapresiasi karyanya. Konteks itulah yang kiranya tidak lagi hadir dalam upaya pembacaan karyanya di era budaya populer. Karenanya, di tengah berbagai keterbatasan tersebut, tulisan ini kiranya diharapkan bisa memberikan kontribusi dalam meneguhkan kesadaran akan pentingnya harmonisasi puisi dan tembang dalam membaca dangding sufistik Mustapa. Sebuah kesadaran akan pentingnya pembacaan atas kreasi

59 Julian Patrick Millie, Splashed by the Saint: Ritual Reading, and Islamic Sanctity in West Java (Disertasi--Leiden University, 2006), 193-194.

60 Robert Wessing, Cosmology and Social Behavior in A West Javanese Settlement (Disertasi--the University of Illinois, Urbana-Champaign, 1974), 286. 
imajinasi sufistik Sunda yang sudah memperkaya khazanah tradisi intelektual Islam Nusantara.

\section{Daftar Rujukan}

Abas, Lutfi. "Prolegomena to Haji Hasan Mustapa's Mystical Cantos". Paper presented at a Seminar in The Department of Malay Studies on October 6, 1976.

Arps, Bernard. Tembang in Two Traditions: Performance and Interpretation of Javanese Literature. London: School of Oriental and African Studies, 1992.

Al-Attas, Syed Muhammad Naguib. The Mysticism of Hamzah Fansuri. Kuala Lumpur: University of Malaya Press, 1970.

al-Bustomi, Ahmad Gibson. "Eksistensi Manusia menurut K.H. Hasan Mustapa". Tesis--UIN Sunan Gunung Djati, Bandung, 2009.

Azra, Azyumardi. The Origins of Islamic Reformism in Southeast Asia: Networks of Malay-Indonesian and Middle Eastern 'Ulama' in the Seventeenth and Eighteenth Centuries. Honolulu: ASAA-Allen \& Unwin and University of Hawai'i Press, 2004.

Benjamin, Walter. Illuminations, Essays, and Reflections. New York: Schocken Books, 1969.

Braginsky, V.I. "Some Remarks on the Structure of the Syair Perahu by Hamzah Fansuri", Bijdragen tot de Taal-, Land-en Volkenkunde 131, No. 4, 1975.

----. Yang Indah, Berfaedah, dan Kamal: Sejarah Sastra Melayu dalam Abad 7-19, terj. Hersri Setiawan. Jakarta: INIS, 1998.

Brouwer, M.A.W. Perjalanan Spiritual dari Gumujeng Sunda, Eksistensi Tuhan, sampai Siberia. Jakarta: KPG, 2003.

Burckhardt, Titus. Introduction to Sufi Doctrine. Indiana: World Wisdom, 2008.

Burhanudin, Jajat. Ulama, dan Kekuasaan: Pergumulan Elite Muslim dalam Sejarah Indonesia. Bandung: Mizan, 2012.

Coolsma, S. Soendaneesch-Hollandsch Woordenboek. Leiden: A.W. Sijthoff's Uitgevers-Maatschappij, 1913.

Corbyn, Henry. Alone with the Alone: Creative Imagination in Sufism of Ibn 'Arabi, terj. Ralph Manheim. Princeton: Princeton University Press, 1969. 
Danasasmita, Ma'mur. Wacana Bahasa, dan Sastra Sunda Lama. Bandung: STSI Press, 2001.

Ekadjati, Edi S. "Sundanese Manuscripts: Their Existence, Functions, and Contents", Journal of the Centre for Documentation \& AreaTranscultural Studies, 2, 2003.

----. Naskah Sunda: Inventarisasi dan Pencatatan. Bandung: Lembaga Penelitian Unpad-The Toyota Foundation, 1988.

Fang, Liaw Yock. Sejarah Kesusasteraan Melayu Klasik. Jakarta: YOI, 1991.

Fathurahman, Oman. Tarekat Shattariyah di Minangkabau. Jakarta: Prenada Media, EFEO, PPIM, KITLV, 2008.

Iskandarwassid, Ajip Rosidi, Josef CD, Naskah Karya Haji Hasan Mustapa. Bandung: Proyek Sundanologi, 1987.

Jahroni, Jajang. "The Life and Mystical Thought of Haji Hasan Mustafa (1852-1930)". Tesis--Leiden University, 1999.

Johns, A.H. "Sufism as a Category in Indonesian Literature, and History", Journal of Southeast Asian History, Vol. 2, No. 2, 1961.

Kartini, Tini, et al. Biografi dan Karya Pujangga Haji Hasan Mustapa. Jakarta: Pusat Pembinaan dan Pengembangan Bahasa Depdikbud, 1985.

Kunto, Haryoto. Semerbak Bunga di Bandung Raya. Bandung: PT. Granesia, 1986.

Laffan, Michael Francis. Islamic Nationhood, and Colonial Indonesia: The Umma below the Winds. London-New York: Routledge Curzon, 2003.

Liem, Maya H.T. The Turning Wheel of Time: Roda Jaman Berputar, Modernity, and Writing Identity in Bali 1900-1970. Leiden: Copy \& Printshop WSD, 2003.

Lubis, Nina H. Kehidupan Menak Priangan 1800-1942. Bandung: Pusat Informasi Kebudayaan Sunda, 1998.

Mas'ud, Abdurrahman. Intelektual Pesantren: Perhelatan Agama dan Tradisi. Yogyakarta: LKiS, 2004.

Meij, Th.C. van Der. Puspakrema: A Javanese Romance from Lombok. Leiden: CNSW Publications, 2002.

Millie, Julian Patrick. Splashed by the Saint: Ritual Readin,g and Islamic Sanctity in West Java. Disertasi--Leiden University, 2006. 
Moriyama, Mikihiro. "Ketika Sastra Dicetak: Perbandingan Tradisi Tulisan Tangan, dan Cetakan dalam Bahasan Sunda pada Paruh Kedua Abad ke-19". Konferensi Kesusastraan XV, Fakultas Sastra Universitas Sam Ratulangi Manado, 2004.

-----. "Print Technology and Literacy in the Second Half of the 19th Century Sundanese Language Community of the Dutch East Indies". 15th Biennal Conference of the Asian Studies Association of Australia, Panel Media Literacy and Community Formation, Canberra: 2004.

-----. Semangat Baru: Kolonialisme, Budaya Cetak, dan Kesastraan Sunda Abad ke-19, terj. Suryadi. Jakarta: KPG, 2005.

Mustapa, Haji Hasan. Bale Bandung. Bandung: Rahmat Cijulang, 1984.

----. Dangding Djilid Anu Kaopat. Bandung: t.p., 1960.

-----. Gendingan Dangding Sunda Birabi Katut Wirahmana Djilid A. Bandung: Jajasan Kudjang, 1976.

-----. Kinanti Tutur teu Kacatur Batur. MS. Or. 7875, UB Leiden, 16 Agustus 1901.

----. Seri Guguritan Haji Hasan Mustapa. Bandung: Kiblat, 2009.

Nicholson, Reynold A. The Mystics of Islam. Indiana: World Wisdom, 2002.

Noorduyn, J., dan Teeuw, A. Tiga Pesona Sunda Kuna, terj. Hawe Setiawan. Jakarta: Pustaka Jaya, 2006.

Ong, Walter J. Orality and Literacy. London, and New York: Routledge, 2002.

Rosidi, Ajip (ed.). Ensiklopedi Sunda: Alam, Budaya, dan Manusia. Jakarta: Pustaka Jaya, 2003.

-----. "Menjejaki Karya-karya Haji Hasan Mustapa", dalam Ahmad Rifa'i Hassan (ed.), Warisan Intelektual Islam Indonesia: Telaah atas Karya-karya Klasik. Bandung: Mizan, 1992.

----. Guguritan. Bandung: Kiblat, 2011.

----. Haji Hasan Mustapa Jeung Karya-karyana. Bandung: Pustaka, 1989.

----. Manusia Sunda. Bandung: Kiblat Pustaka Utama, 2009.

----. Mencari Sosok Manusia Sunda. Bandung: Pustaka Jaya, 2010.

Rusyana, Yus, et al. Lima Abad Sastra Sunda. Bandung: Geger Sunten, 2000), 25. 
Setiawan, Hawe. "Cangkang Suluk Dangding Haji Hasan Mustapa sebagai Wadah Mistisisme Islam”, makalah dalam Sawala Mesek Karya Haji Hasan Mustapa, UIN Bandung, 2009.

Simuh. Mistik Islam Kejawen Raden Ngabehi Ranggawarsita. Jakarta: UIPress, 1988.

Soebardi, S. The Book of Cebolek. Leiden: KITLV-The Hague-Martinus Nijhoof, 1975.

Spiller, Henry. Gamelan: The Traditional Sound of Sunda. California: ABC-CLIO, 2004.

Storey, John. Inventing Popular Culture. UK: Blackwell Publishing, 2003.

Strinati, Dominic. An Introductions to Theories of Popular Culture. London, and New York: Routledge, 1995.

Weintraub, Andrew N. "Tune, Text, and The Function of Lagu in Pantun Sunda: A Sundanese Oral Narrative Tradition", Asian Music, Vol. 26, No. 1, Autumn, 1994-Winter, 1995.

Wessing, Robert. Cosmology, and Social Behavior in A West Javanese Settlement. Disertasi--the University of Illinois, Urbana-Champaign, 1974.

Wirakusumah, Momon, dan Djajawiguna, Buldan. Kandaga Tata Basa Sunda. Bandung: Ganaco, 1957.

Zanten, Wim van. "The Poetry of Tembang Sunda", Bijdragen tot de Taal-, Land-en Volkenkunde 140 (1984), No. 2/3, Leiden, 294.

Zoetmulder, P.J. Manunggaling Kawula Gusti, Pantheisme, dan Monisme dalam Sastra Suluk Jawa, terj. Dick Hartoko. Jakarta: Gramedia Pustaka Utama, 1991. 